\title{
Erratum to: In Memoriam: Dr. Charles Epstein (1933-2011)
}

\author{
Andrea Zanko • Vicki Cox $\cdot$ Beth Crawford · \\ Judy Derstine
}

Published online: 17 November 2011

(C) National Society of Genetic Counselors, Inc. 2011

\section{Erratum to: J Genet Counsel}

DOI 10.1007/s10897-011-9385-6

The authors and editor regret that Charles Epstein's birth year was erroneously given as 1993, when in fact he was born in 1933.

The online version of the original article can be found at http://dx.doi. org/10.1007/s10897-011-9385-6.

A. Zanko $(\triangle) \cdot$ V. Cox $\cdot$ B. Crawford $\cdot$ J. Derstine

Division of Medical Genetics,

University of California Medical Center,

San Francisco, CA, USA

e-mail: zankoa@peds.ucsf.edu 